\title{
Supplementary nutrients for prevention of vascular calcification in patients with chronic kidney disease
}

\author{
Su Mi Lee and Won Suk An
}

Department of Internal Medicine, Dong-A University College of

Medicine, Busan, Korea

Received: April 2, 2019

Accepted: April 13, 2019

\section{Correspondence to}

Won Suk An, M.D.

Department of Internal Medicine, Dong-A University College of Medicine, 32 Daesingongwon-ro, Seo-gu, Busan 49201, Korea

Tel: +82-51-240-2811

Fax: +82-51-242-5852

E-mail: anws@dau.ac.kr

https://orcid.org/0000-0003-

4015-0284

This paper was contributed by The Korean Society of Nephrology.
Vascular calcification (VC) and malnutrition associated with cardiovascular disease are common in patients with chronic kidney disease (CKD) treated with dialysis. VC, which reflects vascular aging, and malnutrition are also encountered in the non-CKD elderly population. This similarity of clinical findings suggests that the progression of CKD is related to aging and the existence of a causal relationship between VC and malnutrition. To retard renal progression, a low- or very-low-protein diet is usually recommended for CKD patients. Dietary education may induce malnutrition and deficiency of important nutrients, such as vitamins $\mathrm{K}$ and $\mathrm{D}$. Menaquinone-7, a type of vitamin $\mathrm{K}_{2}$, is under investigation for inhibiting VC in elderly patients without CKD, as well as for prevention of VC in patients with CKD. Nutritional vitamin D, such as cholecalciferol, may be considered to decrease the required dose of active vitamin $\mathrm{D}$, which increases the risk of VC due to increased calcium and phosphate loads. Omega-3 fatty acids are important nutrients and their ability to inhibit VC needs to be evaluated in clinical trials. This review focuses on the ability of supplementary nutrients to prevent $\mathrm{VC}$ in patients with CKD, in whom dietary restriction is essential.

Keywords: Vascular calcification; Renal insufficiency, chronic; Cholecalciferol; Vitamin K 2; Fatty acids, omega-3

\section{INTRODUCTION}

Patients with chronic kidney disease (CKD) are at greater risk of cardiovascular disease (CVD), as compared to the general population. The mortality rate of a 30 -yearold patient with CKD on dialysis is similar to that of an 8o-year-old person without CKD [1,2]. Vascular calcification (VC) associated with CVD is commonly found in patients with CKD who are on dialysis (Fig. 1). VC of the aorta and coronary artery, which reflects aging of these vessels, is also encountered in elderly persons without CKD (Fig. 1D). Malnutrition is related to CVD and is frequently found in patients with advanced CKD and even in elderly persons without CKD [3]. These epidemiologic findings imply that CKD progression and VC are related to aging. In addition, there is likely to be a causal relationship between VC and malnutrition, particularly in patients with CKD.

Patients with CKD are reluctant to eat high phosphate- and protein-containing foods because of concern over progression of their renal disease. Patients with CKD treated with dialysis are unable to intake sufficient quantities of nutrients because of anorexia and nausea. Dietary education focused on restricting the intake of harmful dietary components, including phosphorous and potassium, may reduce the dietary 


\section{KJIM}
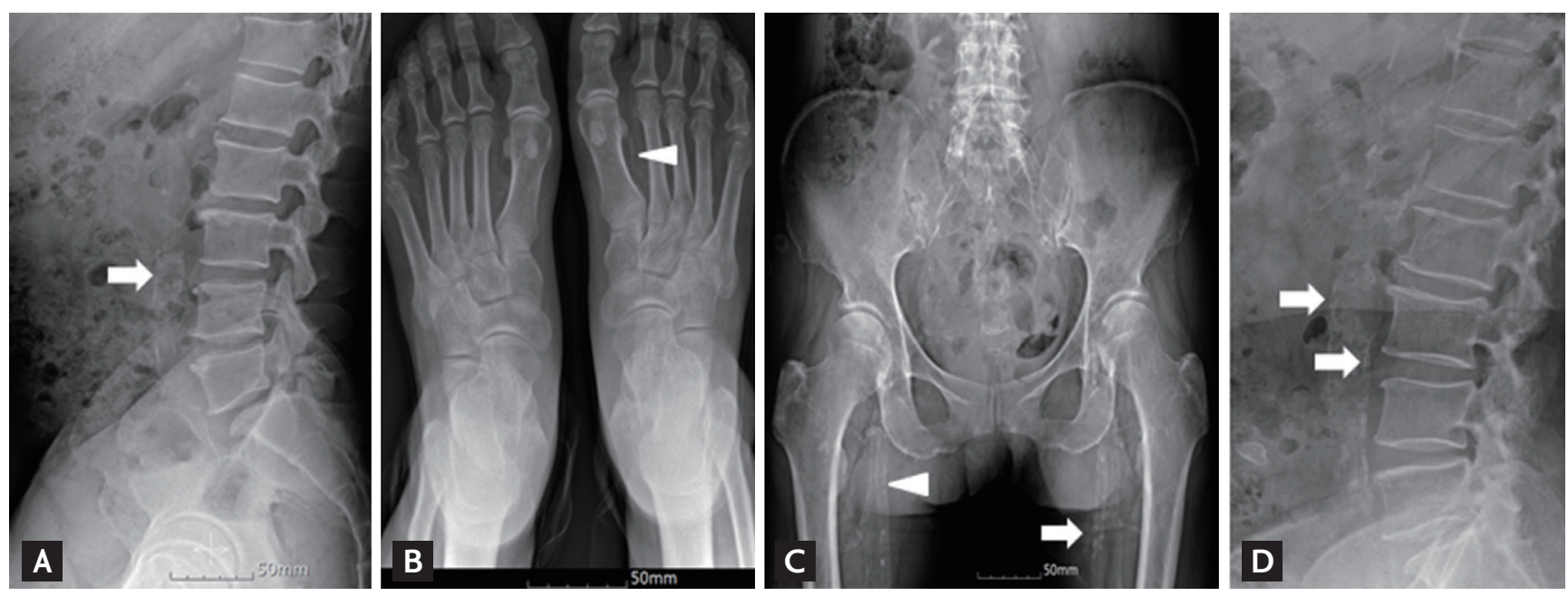

Figure 1. Plain radiographs showing vascular calcification (VC) in patients with chronic kidney disease (CKD) (A-C) and an elderly man without CKD (D). (A) Abdominal aortic calcification (AAC) on a lateral lumbar spine view, (B) arterial medial calcification of the dorsalis pedis artery of the feet, and (C) arterial intimal and medial calcification in the pelvis. (D) AAC in an 86-year-old man without CKD. Arrow, arterial intimal calcification; arrowhead, arterial medial calcification on plain radiographs.

intake. Finally, patients with CKD have deficiencies of important nutrients, such as vitamins $\mathrm{K}$ and $\mathrm{D}$, and so are at high risk of malnutrition. The authors have reviewed supplementary nutrients for prevention of VC in patients with CKD on a restricted diet and poor dietary intake.

\section{EVALUATION OF VASCULAR CALCIFICATION}

The severity of VC can be evaluated by electron beam computed tomography (CT), multi-slice CT, or plain radiographs. Coronary artery calcification (CAC) on CT is associated with coronary plaque accumulation and a poor outcome in patients with CKD [4,5]. VC is easily evaluated using plain radiographs, which are inexpensive and involve less exposure to radiation than CT. Plain radiographs of the lateral lumbar spine, hands and pelvis (HP), feet, and chest, can be used to evaluate and score $\mathrm{VC}$ [6-12]. The abdominal aortic calcification (AAC) or HP VC score on plain radiographs is associated with coronary artery disease $(\mathrm{CAD})$ in patients on dialysis $[6,13,14]$. The presence of VC on plain radiographs of the feet is associated with peripheral artery disease as well as CAD $[9,10]$. Among the various VC scoring systems, the AAC score on plain radiographs of the lateral lumbar spine is predictive of CAC on CT and the T-score (an indicator of bone mineral density) of the forearm $[15,16]$. The 2017 Kidney Disease: Improving Global Outcomes (KDIGO) guidelines recommend that VC be evaluated using a lateral view of the lumbar spine [17]. Plain radiographs are also useful for monitoring of VC progression [18]. Patients on dialysis with advanced VC are at increased risk of mortality [19].

VC may manifest as arterial intimal or medial calcification $[20,21]$. Arterial intimal calcification is found in the coronary arteries, carotid arteries, and aorta, and arterial medial calcification in the peripheral arteries of the hands and feet [22]. Ring-like calcification of the dorsalis pedis artery or linear railroad-track form calcification on plain radiographs indicates arterial medial calcification (Fig. 1). On plain radiographs, arterial intimal calcification appears as areas of irregular and patchy density (Fig. 1).

\section{RISK FACTORS FOR VASCULAR CALCIFICATION}

Arterial intimal and medial calcification often coexist in patients with CKD; however, whether these entities share risk factors is unclear. Traditional risk factors, such as aging, diabetes mellitus, hypertension, and dyslipidemia, as well as inflammation, oxidative stress, klotho deficiency, and high calcium and phosphate 
loads play crucial roles in the pathogenesis of intimal and medial VC [23-25]. VC is prevalent in diabetic patients with CKD and hyperglycemia induces the development and progression of VC [26].

Hyperphosphatemia is a risk factor for death in both the general population and in patients with CKD [27,28], and can worsen VC [29,30]. Egg white has an ideal phosphorus-to-protein ratio ( $1.42 \mathrm{mg} / \mathrm{g}$ protein), while red meat, pork, and poultry have low levels of phosphorus (4.1 to $9.2 \mathrm{mg} / \mathrm{g}$ protein) [31,32]. However, these foods have several additives that contain inorganic phosphorus, which is readily absorbed in the intestine. The acceptable phosphorus-to-protein ratio of food in terms of minimizing the risk of $\mathrm{VC}$ is $<16 \mathrm{mg} / \mathrm{g}$, and reducing the use of food additives containing inorganic phosphorus is important.

Use of calcium-free phosphate binders decreases mortality and retards the progression of VC compared to calcium-containing phosphate binders in patients on dialysis [33,34]. The 2017 KDIGO guidelines recommend restriction of the use of calcium-based phosphate binders to reduce the phosphorus level [17]. Differentiation of vascular smooth muscle cells to osteoblast-like cells is involved in the pathogenesis of $\mathrm{VC}$ and calcium may precipitate on the osteoblast-like cell. An elevated calcium load due to use of calcium-containing phosphate binders, high-dose active vitamin D analogs, and a high dialysate calcium concentration can accelerate the progression of VC. Use of low dialysate calcium ( $1.25 \mathrm{mmol} / \mathrm{L})$ may reduce the progression of CAC in patients on hemodialysis (HD) [35,36]. The progression of CAC after use of low dialysate calcium $(1.25 \mathrm{mmol} /$ L) compared to standard dialysate calcium $(1.5 \mathrm{mmol} / \mathrm{L})$ has been investigated in patients on HD [37]. However, patients in the low-calcium dialysate group received higher doses of calcium-containing phosphate binders or calcitriol. To avoid unnecessary calcium loading, the most recent KDIGO guidelines recommend that mild and asymptomatic hypocalcemia not be treated.

\section{NUTRIENT DEFICIENCY AND VASCULAR CAL- CIFICATION}

\section{Protein restriction and vascular calcification}

The KDIGO recommends lowering protein intake to
$0.8 \mathrm{~g} / \mathrm{kg} /$ day in patients with CKD with a glomerular filtration rate of $<30 \mathrm{~mL} / \mathrm{min} / 1.73 \mathrm{~m}^{2}$ and limiting protein intake to $1.3 \mathrm{~g} / \mathrm{kg} /$ day in adults with CKD at risk of progression [38]. Excess dietary protein intake leads to the retention of nitrogenous metabolites and uremic toxins. In contrast, insufficient protein intake can result in loss of lean body mass, deficiencies of essential nutrients, inflammation, and VC in patients with CKD [39,40]. Induction (by feeding $0.75 \%$ adenine for 4 weeks) of arterial medial calcification in uremic rats dramatically increased the frequency and severity without significantly affecting the elevated serum creatinine, phosphate, and parathyroid hormone (PTH) levels after changing dietary protein composition from $25 \%$ to $2.5 \%$ [41]. Therefore, only a very-low-protein diet (VLPD) induces VC in the presence of uremia; however, the underlying mechanism needs to be elucidated. Physicians and dieticians encourage patients with CKD to avoid foods containing high phosphate, potassium, salt, and protein levels $[42,43]$. Intake of green leafy vegetables with high levels of vitamin $\mathrm{K}$ increases the risk of hyperkalemia, and intake of cheese with high levels of vitamins $\mathrm{K}$ and $\mathrm{D}$ increases the serum phosphate level. However, strict education on dietary restriction may induce malnutrition and deficiency of important nutrients such as vitamin $\mathrm{K}$ and nutritional vitamin $\mathrm{D}$, which is related to VC.

In a recent randomized control trial, a ketoanalogue -supplemented vegetarian VLPD ( 0.3 to $0.4 \mathrm{~g} / \mathrm{kg} /$ day) in patients with high compliance slowed CKD progression compared to a conventional low-protein diet $(0.6 \mathrm{~g} /$ $\mathrm{kg} /$ day) $[44,45]$. Notably, nutritional vitamin $\mathrm{K}$ and vitamin D replacement with pills (such as a ketoanalogue) should be considered to prevent VC when physicians and dieticians recommend VLPD to delay the need for dialysis in patients with CKD.

\section{Vitamin D and vascular calcification}

As renal function declines, phosphate retention results in increased levels of fibroblast growth factor-23 (FGF23) and PTH. In addition, the decreased serum-free calcium level caused by reduced production of calcitriol and increased catabolism of active vitamin $\mathrm{D}$ in patients with CKD activates PTH secretion [46]. A normal serum phosphate level is maintained in patients with mild-to-moderate CKD because of the elevated serum 
PTH and FGF-23 levels. The 2009 KDIGO guidelines recommend that secondary hyperparathyroidism (SHPT) in patients with CKD can be controlled using calcitriol and vitamin D analogs [47]. Calcitriol and other $1 \alpha$-hydroxylated vitamin D sterols, such as $1 \alpha$-hydroxyvitamin $\mathrm{D}_{3}$ (alfacalcidol), 1 $\alpha$-hydroxyvitamin $\mathrm{D}_{2}$ (doxercalciferol), and 19-nor-1 $\alpha$-25-dihydroxyvitamin $\mathrm{D}_{2}$ (paricalcitol), are commonly prescribed for SHPT. Indeed, oral calcitriol use may be positively associated with survival in patients with CKD $[48,49]$. However, these drugs not only increase the risk of hypercalcemia but also do not improve the clinical outcomes. Therefore, the 2017 KDIGO guidelines recommend use of calcitriol and vitamin D analogs exclusively in patients with severe and progressive SHPT [17]. Calcimimetics such as cinacalcet are the first-line therapy to reduce the PTH level. Cinacalcet binds to the transmembrane region of the calcium-sensing receptor. While treatment with vitamin D analogs reduces the PTH level but can lead to the development of VC by increasing the intestinal absorption of calcium and phosphate [5052], cinacalcet reduces the PTH level and decreases the serum calcium and phosphorus levels [53]. Analogues of calcitriol, such as doxecalciferol, paricalcitol, and maxacalcitol, have less calcemic activity than calcitriol. Maxacalcitol, previously called 22-oxacalcitriol, ameliorates VC to a greater degree than calcitriol despite their comparable ability to control the levels of PTH and calcium-phosphate products [51]. This may be due to the differential effects of vitamin $\mathrm{D}$ receptor activators on VC in the presence of uremia. Paricalcitol and doxecalciferol are analogs in the vitamin $\mathrm{D}_{2}$ family; however, paricalcitol induces a greater reduction in calcium and phosphate levels and amelioration of VC than doxecalciferol $[54,55]$. Combination treatment with cinacalcet and a low dose of active vitamin $\mathrm{D}$ reportedly decreases the Agatston CAC score and the volume CAC score compared to flexible higher-dose active vitamin D monotherapy in HD patients [56]. This suggests that higher-dose active vitamin D monotherapy without cinacalcet influences the calcification score by increasing the calcium and phosphate loads.

Use of nutritional vitamin $\mathrm{D}$, such as ergocalciferol and cholecalciferol, can decrease the required dose of active vitamin D (Fig. 2). Supplementation of nutritional vitamin D reportedly improves the vitamin D status and decreases the PTH level in patients with CKD [576o]. In particular, cholecalciferol supplementation in patients on dialysis allowed the dose of active vitamin $\mathrm{D}$ to be reduced and did not increase the calcium or phosphate level [61]. In a recent study, treatment with cinacalcet, calcitriol, and cholecalciferol accelerated achievement of the target PTH $(\leq 300 \mathrm{pg} / \mathrm{mL})$, reduced the mean dose of calcitriol, increased the 25 -hydroxyvitamin D level, and increased the femur-neck bone density compared to cinacalcet, calcitrol, and placebo [62]. The changes in calcium and phosphorus levels were similar in the two treatment arms. Reduced use of active vitamin D may prevent VC. Therefore, nutritional vitamin D can be considered an alternative to active vitamin D. Vitamin D therapy should be carefully prescribed, and strict control of the patient's calcium and phosphate intake is necessary. Further studies are needed to determine whether nutritional vitamin D supplementation slows the development or progression of VC.

\section{Vitamin $\mathrm{K}$ and vascular calcification}

The vitamin $\mathrm{K}$ group is composed of phylloquinone (vitamin $\mathrm{K}_{1}$ ), several menaquinones ( $\mathrm{MK}$, vitamin $\mathrm{K}_{2}$ ), and synthetic forms, such as menadion (vitamin $\mathrm{K}_{3}$ ) and esterified menadion (vitamin $\mathrm{K}_{4}$ ). The main sources of dietary vitamin $\mathrm{K}_{1}$ are green leafy vegetables and some plant oils, while dietary vitamin $\mathrm{K}_{2}$ is abundant in fermented foods, such as cheese and Japanese natto [63,64]. Phylloquinone is converted into MK-4. The characteristics of MKs are dependent on the number of isoprenoid residues in the side chain. For example, MK-7 has a half-life of 3 days and MK-4 of 1 hour. Among the several isoforms of MK-n and long-chain MKs, human foods are particularly rich in MK-7.

Although the data are controversial, accumulating evidence suggests that a low vitamin $\mathrm{K}$ level is associated with osteoporosis and increased risk of fracture, CVD, and mortality [65-67]. A high dietary vitamin K intake may benefit bone and vascular health. Indeed, a relationship between diet-induced vitamin $\mathrm{K}$ deficiency and VC has been reported $[67,68]$. In patients on dialysis, a low vitamin $\mathrm{K}$ intake may be related to VC [69,70]. Warfarin, a vitamin $\mathrm{K}$ antagonist, can induce calciphylaxis, also known as calcific uremic arteriopathy, which is a life-threatening, rare complication of end-stage renal disease $[71,72]$. In this respect, dietary vitamin $\mathrm{K}$ 


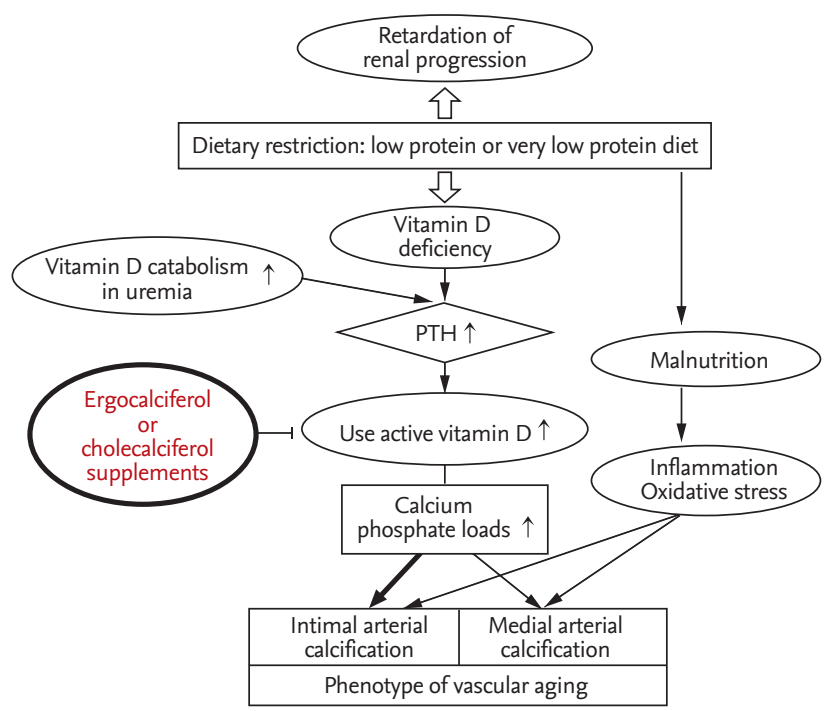

Figure 2. Mechanism by which vitamin D modulates arterial intimal and medial calcification in patients with chronic kidney disease. Bold arrow indicates more related with arterial intimal vascular calcification than thin arrow. Bold circle nutritional vitamin $\mathrm{D}$ for prevention of vascular calcification in patients with chronic kidney disease. PTH, parathyroid hormone.

supplementation has a beneficial effect on VC [73]. In mammals, vitamin $\mathrm{K}$ serves as a cofactor for $\gamma$-glutamyl carboxylation, which converts glutamate into $\gamma$-carboxyglutamate (Gla). Under vitamin K insufficiency, undercarboxylated Gla-proteins, such as uncarboxylated osteocalcin (OC) and desphosphorylated-uncarboxylated matrix Gla-protin (MGP) are released in the circulation because of reduced carboxylation. The circulating levels of undercarboxylated Gla-proteins are associated with poor bone and vascular health [74-77]. VC is positively associated with the levels of undercarboxylated Gla-proteins and medial arterial calcification occurs in areas of deposition of undercarboxylated Gla-proteins. In contrast, increased vitamin $\mathrm{K}$ intake can increase carboxylation of OC and MGP (Fig. 3) [78-81]. Moreover, MK-7 may be the optimal form for dietary supplementation because of its long half-life. MK-7 supplementation decreased the desphosphorylated-uncarboxylated MGP levels in patients on chronic HD [73]. MK-7 (360 $\mu \mathrm{g})$ is also under investigation for prevention of $\mathrm{VC}$ in patients with a baseline Agatston CAC score of 50 to 400 [82]. Therefore, MK-7 shows promise for the prevention of VC in patients with CKD. However, studies of the

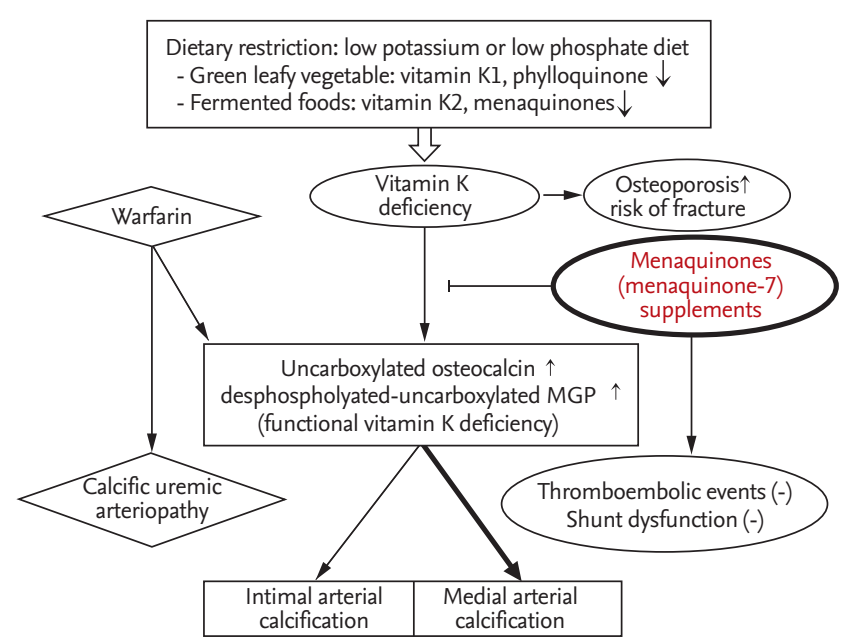

Figure 3. Mechanism by which vitamin K modulates arterial intimal and medial calcification in patients with chronic kidney disease. Bold arrow indicates more related with arterial medial vascular calcification than thin arrow. Bold circle, vitamin $\mathrm{K}$ for prevention of vascular calcification in patients with chronic kidney disease. MGP, matrix $\gamma$-carboxyglutamate protein.

efficacy and safety of vitamin K supplementation in patients with CKD are lacking and so further prospective research is needed.

\section{Fatty acids and vascular calcification}

Among the risk factors for CVD, dyslipidemia plays a crucial role in CAC $[83,84]$. Atherosclerotic lesions with cholesterol and lipid deposition are also associated with VC $[85,86]$. Omega-3 fatty acids (FAs) was used for the treatment of a lipid abnormality characterized by hypertriglyceridemia in patients with CKD $[83,87]$ and it decreased aortic calcification and warfarin induced medial arterial calcification in a rat model $[88,89]$. The content of oleic acid, a monounsaturated fatty acid (MUFA), in the erythrocyte membrane was significantly higher in patients with acute coronary syndrome and those on dialysis [90-93]. MUFA is endogenously synthesized from dietary carbohydrates and saturated FA intakes, and this process can be aggravated in the presence of uremia $[94,95]$. Omega-3 FAs, such as eicosapentaenoic acid (EPA) and docosahexaenoic acid (DHA), decrease the oleic-acid level in patients on dialysis $[96,97]$. Moreover, the erythrocyte membrane contents of MUFAs, 


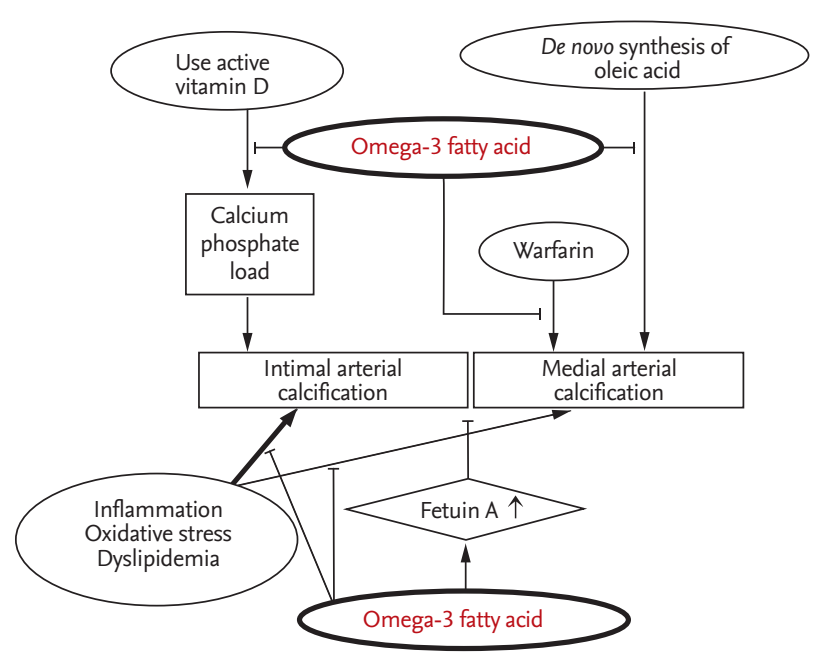

Figure 4. Mechanism by which omega-3 fatty acids modulate arterial intimal and medial calcification in patients with chronic kidney disease. Supplementation of several nutrients may be more useful for prevention of vascular calcification.

including oleic acid, were significantly higher in patients with arterial medial calcification of the feet than in those without calcifications [93]. Therefore, omega-3 FAs not only control the erythrocyte membrane FA content but also ameliorate VC.

VC is associated with arterial stiffness and an increased CV risk [98], while an EPA- or DHA-rich diet ameliorates arterial stiffness [99,100]. Fetuin-A, which is synthesized in the liver, is a circulating inhibitor of VC [101]. In patients on dialysis, a low fetuin-A level is associated with malnutrition, arterial stiffness, VC, and mortality [102-104]. We reported previously that omega-3 FA supplementation increases the fetuin-A and 1, 25 dihydroxyvitamin D levels in patients on dialysis [96], suggesting that omega-3 FA supplementation activates vitamin D. Co-supplementation of omega-3 FA and cholecalciferol may have a clinical benefit by activating vitamin $\mathrm{D}$, increasing the fetuin-A level, modifying the erythrocyte membrane FA content, and reducing use of active vitamin D (Fig. 4). Further clinical trials to identify the role of omega-3 FA in VC are needed.

This review was limited by being based on mainly experimental studies; few clinical studies of VC prevention using supplementary nutrients in patients with CKD were analyzed.

\section{CONCLUSIONS}

Nutritional management, such as a VLPD, may be necessary to delay the progression of renal disease; however, deficiencies in essential nutrients, such vitamins $\mathrm{K}_{2}$ and D, must be overcome to prevent VC. Cholecalciferol, MK, and omega-3 FA are promising supplementary nutrients for preventing VC in patients with CKD. Further studies are needed to clarify the ability of supplementary nutrients to prevent intimal or medial VC in patients with CKD.

\section{Conflict of interest}

No potential conflict of interest relevant to this article was reported.

\section{Acknowledgments}

This work was supported by the Dong-A University research fund.

\section{REFERENCES}

1. Foley RN, Parfrey PS, Sarnak MJ. Clinical epidemiology of cardiovascular disease in chronic renal disease. Am J Kidney Dis 1998;32(5 Suppl 3):S112-S119.

2. Jin DC, Yun SR, Lee SW, et al. Current characteristics of dialysis therapy in Korea: 2016 registry data focusing on diabetic patients. Kidney Res Clin Pract 2018;37:20-29.

3. Lee MJ, Kwon YE, Park KS, et al. Changes in geriatric nutritional risk index and risk of major adverse cardiac and cerebrovascular events in incident peritoneal dialysis patients. Kidney Res Clin Pract 2017;36:377-386.

4. Russo D, Palmiero G, De Blasio AP, Balletta MM, Andreucci VE. Coronary artery calcification in patients with CRF not undergoing dialysis. Am J Kidney Dis 2004;44:1024-1030.

5. Fox CS, Larson MG, Keyes MJ, et al. Kidney function is inversely associated with coronary artery calcification in men and women free of cardiovascular disease: the Framingham Heart Study. Kidney Int 2004;66:2017-2021.

6. Honkanen E, Kauppila L, Wikstrom B, et al. Abdominal aortic calcification in dialysis patients: results of the CORD study. Nephrol Dial Transplant 2008;23:4009-4015.

7. Verbeke F, Van Biesen W, Honkanen E, et al. Prognostic value of aortic stiffness and calcification for cardiovascu- 
lar events and mortality in dialysis patients: outcome of the calcification outcome in renal disease (CORD) study. Clin J Am Soc Nephrol 2011;6:153-159.

8. Adragao T, Pires A, Lucas C, et al. A simple vascular calcification score predicts cardiovascular risk in haemodialysis patients. Nephrol Dial Transplant 2004;19:1480-1488.

9. An WS, Kim SE, Kim KH, Bae HR, Rha SH. Associations between oxidized LDL to LDL ratio, HDL and vascular calcification in the feet of hemodialysis patients. J Korean Med Sci 2009;24 Suppl:S115-S120.

10. An WS, Son YK, Kim SE, et al. Vascular calcification score on plain radiographs of the feet as a predictor of peripheral arterial disease in patients with chronic kidney disease. Int Urol Nephrol 2010;42:773-780.

11. Ogawa T, Ishida H, Matsuda N, et al. Simple evaluation of aortic arch calcification by chest radiography in hemodialysis patients. Hemodial Int 2009;13:301-306.

12. Nitta K, Ogawa T. Aortic arch calcification and clinical outcome in patients with end-stage renal disease. Tohoku J Exp Med 2011;223:79-84.

13. Kim SC, Chang HJ, Kim MG, Jo SK, Cho WY, Kim HK. Relationship between pulmonary hypertension, peripheral vascular calcification, and major cardiovascular events in dialysis patients. Kidney Res Clin Pract 2015;34:28-34.

14. Adragao T, Pires A, Birne R, et al. A plain X-ray vascular calcification score is associated with arterial stiffness and mortality in dialysis patients. Nephrol Dial Transplant 2009;24:997-1002.

15. Lee SM, Lee HW, Son YK, Kim SE, An WS. Abdominal aortic calcification score among several vascular calcification scores of plain radiograph is the most reliable predictor of severe coronary artery calcification in dialysis patients. Ren Fail 2017;39:729-735.

16. Russo D, Morrone LF, Brancaccio S, et al. Pulse pressure and presence of coronary artery calcification. Clin J Am Soc Nephrol 2009;4:316-322.

17. Kidney Disease: Improving Global Outcomes (KDIGO) CKD-MBD Update Work Group. KDIGO 2017 clinical practice guideline update for the diagnosis, evaluation, prevention, and treatment of Chronic Kidney Disease-Mineral and Bone Disorder (CKD-MBD). Kidney Int Suppl (2011) 2017;7:1-59.

18. An WS, Son YK. Vascular calcification on plain radiographs is associated with carotid intima media thickness, malnutrition and cardiovascular events in dialysis patients: a prospective observational study. BMC Nephrol
2013;14:27.

19. Noordzij M, Cranenburg EM, Engelsman LF, et al. Progression of aortic calcification is associated with disorders of mineral metabolism and mortality in chronic dialysis patients. Nephrol Dial Transplant 2011;26:16621669.

20. Amann K. Media calcification and intima calcification are distinct entities in chronic kidney disease. Clin J Am Soc Nephrol 2008;3:1599-1605.

21. Lee JY, Kim YO. Pre-existing arterial pathologic changes affecting arteriovenous fistula patency and cardiovascular mortality in hemodialysis patients. Korean J Intern Med 2017;32:790-797.

22. Shanahan CM, Cary NR, Salisbury JR, Proudfoot D, Weissberg PL, Edmonds ME. Medial localization of mineralization-regulating proteins in association with Monckeberg's sclerosis: evidence for smooth muscle cell-mediated vascular calcification. Circulation 1999;100:2168-2176.

23. London GM, Guerin AP, Marchais SJ, Metivier F, Pannier B, Adda H. Arterial media calcification in end-stage renal disease: impact on all-cause and cardiovascular mortality. Nephrol Dial Transplant 2003;18:1731-1740.

24. Keelan PC, Bielak LF, Ashai K, et al. Long-term prognostic value of coronary calcification detected by electron-beam computed tomography in patients undergoing coronary angiography. Circulation 2001;104:412-417.

25. Guerin AP, London GM, Marchais SJ, Metivier F. Arterial stiffening and vascular calcifications in end-stage renal disease. Nephrol Dial Transplant 2000;15:1014-1021.

26. Hayden MR, Tyagi SC, Kolb L, Sowers JR, Khanna R. Vascular ossification-calcification in metabolic syndrome, type 2 diabetes mellitus, chronic kidney disease, and calciphylaxis-calcific uremic arteriolopathy: the emerging role of sodium thiosulfate. Cardiovasc Diabetol 2005;4:4.

27. Tonelli M, Sacks F, Pfeffer M, Gao Z, Curhan G; Cholesterol And Recurrent Events Trial Investigators. Relation between serum phosphate level and cardiovascular event rate in people with coronary disease. Circulation 2005;112:2627-2633.

28. Kestenbaum B, Sampson JN, Rudser KD, et al. Serum phosphate levels and mortality risk among people with chronic kidney disease. J Am Soc Nephrol 2005;16:520528.

29. Hruska KA, Saab G, Mathew S, Lund R. Renal osteodystrophy, phosphate homeostasis, and vascular calcification. Semin Dial 2007;20:309-315. 
30. Kovesdy CP, Kalantar-Zadeh K. Serum phosphorus and the risk of progression of chronic kidney disease. Nephrol Dial Transplant 2007;22:3679-3680.

31. Barril-Cuadrado G, Puchulu MB, Sanchez-Tomero JA. Table showing dietary phosphorus/protein ratio for the Spanish population. Usefulness in chronic kidney disease. Nefrologia 2013;33:362-371.

32. Hwang E, Choi BS, Oh KH, Kwon YJ, Kim GH. Management of chronic kidney disease-mineral and bone disorder: Korean working group recommendations. Kidney Res Clin Pract 2015;34:4-12.

33. Block GA, Raggi P, Bellasi A, Kooienga L, Spiegel DM. Mortality effect of coronary calcification and phosphate binder choice in incident hemodialysis patients. Kidney Int 2007;71:438-441.

34. Chertow GM, Raggi P, Chasan-Taber S, Bommer J, Holzer H, Burke SK. Determinants of progressive vascular calcification in haemodialysis patients. Nephrol Dial Transplant 2004;19:1489-1496.

35. Ok E, Asci G, Bayraktaroglu S, et al. Reduction of dialysate calcium level reduces progression of coronary artery calcification and improves low bone turnover in patients on hemodialysis. J Am Soc Nephrol 2016;27:2475-2486.

36. Kim JK, Moon SJ, Park HC, et al. Effects of lowering dialysate calcium concentrations on arterial stiffness in patients undergoing hemodialysis. Korean J Intern Med 2011;26:320-327.

37. Kim SJ, Lee YK, Oh J, Cho A, Noh JW. Effects of low calcium dialysate on the progression of coronary artery calcification in hemodialysis patients: an open-label 12-month randomized clinical trial. Int J Cardiol 2017;243:431-436.

38. Kidney Disease: Improving Global Outcomes (KDIGO) CKD Work Group. KDIGO 2012 clinical practice guideline for the evaluation and management of chronic kidney disease. Kidney Int Suppl 2013;3:1-150.

39. Shinaberger CS, Kilpatrick RD, Regidor DL, et al. Longitudinal associations between dietary protein intake and survival in hemodialysis patients. Am J Kidney Dis 2006;48:37-49.

40. Kalantar-Zadeh K, Ikizler TA, Block G, Avram MM, Kopple JD. Malnutrition-inflammation complex syndrome in dialysis patients: causes and consequences. Am J Kidney Dis 2003;42:864-881.

41. Price PA, Roublick AM, Williamson MK. Artery calcification in uremic rats is increased by a low protein diet and prevented by treatment with ibandronate. Kidney Int
2006;70:1577-1583.

42. Karavetian M, Rizk R. Patient education for hyperphosphatemia management: improving outcomes while decreasing costs? Kidney Res Clin Pract 2018;37:4-7.

43. Lim E, Hyun S, Lee JM, et al. Effects of education on low-phosphate diet and phosphate binder intake to control serum phosphate among maintenance hemodialysis patients: a randomized controlled trial. Kidney Res Clin Pract 2018;37:69-76.

44. Garneata L, Stancu A, Dragomir D, Stefan G, Mircescu G. Ketoanalogue-supplemented vegetarian very low-protein diet and CKD progression. J Am Soc Nephrol 2016;27:2164-2176.

45. Satirapoj B, Vongwattana P, Supasyndh O. Very low protein diet plus ketoacid analogs of essential amino acids supplement to retard chronic kidney disease progression. Kidney Res Clin Pract 2018;37:384-392.

46. Helvig CF, Cuerrier D, Hosfield CM, et al. Dysregulation of renal vitamin $\mathrm{D}$ metabolism in the uremic rat. Kidney Int 2010;78:463-472.

47. Kidney Disease: Improving Global Outcomes (KDIGO) CKD-MBD Work Group. KDIGO clinical practice guideline for the diagnosis, evaluation, prevention, and treatment of Chronic Kidney Disease-Mineral and Bone Disorder (CKD-MBD). Kidney Int Suppl 2009;76(Suppl 113):S1-S130.

48. Shoben AB, Rudser KD, de Boer IH, Young B, Kestenbaum B. Association of oral calcitriol with improved survival in nondialyzed CKD. J Am Soc Nephrol 2008;19:16131619 .

49. Kovesdy CP, Ahmadzadeh S, Anderson JE, Kalantar-Zadeh K. Association of activated vitamin $\mathrm{D}$ treatment and mortality in chronic kidney disease. Arch Intern Med 2008;168:397-403.

50. Henley C, Colloton M, Cattley RC, et al. 1,25-Dihydroxyvitamin $\mathrm{D}_{3}$ but not cinacalcet $\mathrm{HCl}$ (Sensipar/Mimpara) treatment mediates aortic calcification in a rat model of secondary hyperparathyroidism. Nephrol Dial Transplant 2005;20:1370-1377.

51. Hirata M, Katsumata K, Endo K, Fukushima N, Ohkawa $\mathrm{H}$, Fukagawa M. In subtotally nephrectomized rats 22-oxacalcitriol suppresses parathyroid hormone with less risk of cardiovascular calcification or deterioration of residual renal function than 1,25 $(\mathrm{OH})_{2}$ vitamin $\mathrm{D}_{3}$. Nephrol Dial Transplant 2003;18:1770-1776.

52. Tukaj C, Kubasik-Juraniec J, Kraszpulski M. Morpholog- 
ical changes of aortal smooth muscle cells exposed to calcitriol in culture. Med Sci Monit 2000;6:668-674.

53. Wetmore JB, Gurevich K, Sprague S, et al. A randomized trial of cinacalcet versus vitamin $\mathrm{D}$ analogs as monotherapy in secondary hyperparathyroidism (PARADIGM). Clin J Am Soc Nephrol 2015;10:1031-1040.

54. Mizobuchi M, Finch JL, Martin DR, Slatopolsky E. Differential effects of vitamin D receptor activators on vascular calcification in uremic rats. Kidney Int 2007;72:709-715.

55. Wu-Wong JR, Noonan W, Ma J, et al. Role of phosphorus and vitamin $\mathrm{D}$ analogs in the pathogenesis of vascular calcification. J Pharmacol Exp Ther 2006;318:90-98.

56. Raggi P, Chertow GM, Torres PU, et al. The ADVANCE study: a randomized study to evaluate the effects of cinacalcet plus low-dose vitamin $\mathrm{D}$ on vascular calcification in patients on hemodialysis. Nephrol Dial Transplant 2011;26:1327-1339.

57. Garcia-Lopes MG, Pillar R, Kamimura MA, et al. Cholecalciferol supplementation in chronic kidney disease: restoration of vitamin D status and impact on parathyroid hormone. Ann Nutr Metab 2012;61:74-82.

58. Dogan E, Erkoc R, Sayarlioglu H, Soyoral Y, Dulger H. Effect of depot oral cholecalciferol treatment on secondary hyperparathyroidism in stage 3 and stage 4 chronic kidney diseases patients. Ren Fail 2008;30:407-410.

59. Oksa A, Spustova V, Krivosikova Z, et al. Effects of longterm cholecalciferol supplementation on mineral metabolism and calciotropic hormones in chronic kidney disease. Kidney Blood Press Res 2008;31:322-329.

6o. Zheng JQ, Hou YC, Zheng CM, et al. Cholecalciferol additively reduces serum parathyroid hormone and increases vitamin D and cathelicidin levels in paricalcitol-treated secondary hyperparathyroid hemodialysis patients. Nutrients 2016;8:E708.

61. Matias PJ, Jorge C, Ferreira C, et al. Cholecalciferol supplementation in hemodialysis patients: effects on mineral metabolism, inflammation, and cardiac dimension parameters. Clin J Am Soc Nephrol 2010;5:905-911.

62. Zheng CM, Wu CC, Hung CF, et al. Cholecalciferol additively reduces serum parathyroid hormone levels in severe secondary hyperparathyroidism treated with calcitriol and cinacalcet among hemodialysis patients. Nutrients 2018;10.

63. Schurgers LJ, Vermeer C. Determination of phylloquinone and menaquinones in food. Effect of food matrix on circulating vitamin $\mathrm{K}$ concentrations. Haemostasis
2000;30:298-307.

64. Krueger T, Westenfeld R, Ketteler M, Schurgers LJ, Floege J. Vitamin K deficiency in CKD patients: a modifiable risk factor for vascular calcification? Kidney Int 2009;76:18-22.

65. Binkley NC, Suttie JW. Vitamin K nutrition and osteoporosis. J Nutr 1995;125:1812-1821.

66. Feskanich D, Weber P, Willett WC, Rockett H, Booth SL, Colditz GA. Vitamin K intake and hip fractures in women: a prospective study. Am J Clin Nutr 1999;69:74-79.

67. Geleijnse JM, Vermeer C, Grobbee DE, et al. Dietary intake of menaquinone is associated with a reduced risk of coronary heart disease: the Rotterdam Study. J Nutr 2004;134:3100-3105.

68. Braam LA, Hoeks AP, Brouns F, Hamulyak K, Gerichhausen MJ, Vermeer C. Beneficial effects of vitamins D and K on the elastic properties of the vessel wall in postmenopausal women: a follow-up study. Thromb Haemost 2004;91:373-380.

69. Cranenburg EC, Schurgers LJ, Uiterwijk HH, et al. Vitamin $\mathrm{K}$ intake and status are low in hemodialysis patients. Kidney Int 2012;82:605-610.

70. Pilkey RM, Morton AR, Boffa MB, et al. Subclinical vitamin K deficiency in hemodialysis patients. Am J Kidney Dis 2007;49:432-439.

71. Saifan C, Saad M, El-Charabaty E, El-Sayegh S. Warfarin-induced calciphylaxis: a case report and review of literature. Int J Gen Med 2013;6:665-669.

72. Mehta RL, Scott G, Sloand JA, Francis CW. Skin necrosis associated with acquired protein $\mathrm{C}$ deficiency in patients with renal failure and calciphylaxis. Am J Med 1990;88:252-257.

73. Caluwe R, Vandecasteele S, Van Vlem B, Vermeer C, De Vriese AS. Vitamin K2 supplementation in haemodialysis patients: a randomized dose-finding study. Nephrol Dial Transplant 2014;29:1385-1390.

74. Booth SL, Broe KE, Peterson JW, et al. Associations between vitamin $\mathrm{K}$ biochemical measures and bone mineral density in men and women. J Clin Endocrinol Metab 2004;89:4904-4909.

75. Vergnaud P, Garnero P, Meunier PJ, Breart G, Kamihagi K, Delmas PD. Undercarboxylated osteocalcin measured with a specific immunoassay predicts hip fracture in elderly women: the EPIDOS Study. J Clin Endocrinol Metab 1997;82:719-724.

76. Cranenburg EC, Vermeer C, Koos R, et al. The circulating inactive form of matrix Gla protein (ucMGP) as a 
biomarker for cardiovascular calcification. J Vasc Res 2008;45:427-436.

77. Cranenburg EC, Koos R, Schurgers LJ, et al. Characterisation and potential diagnostic value of circulating matrix Gla protein (MGP) species. Thromb Haemost 2010;104:811-822.

78. Booth SL, O'Brien-Morse ME, Dallal GE, Davidson KW, Gundberg CM. Response of vitamin K status to different intakes and sources of phylloquinone-rich foods: comparison of younger and older adults. Am J Clin Nutr 1999;70:368-377.

79. Sokoll LJ, Booth SL, O’Brien ME, Davidson KW, Tsaioun KI, Sadowski JA. Changes in serum osteocalcin, plasma phylloquinone, and urinary gamma-carboxyglutamic acid in response to altered intakes of dietary phylloquinone in human subjects. Am J Clin Nutr 1997;65:779-784.

8o. Westenfeld R, Krueger T, Schlieper G, et al. Effect of vitamin K2 supplementation on functional vitamin K deficiency in hemodialysis patients: a randomized trial. Am J Kidney Dis 2012;59:186-195.

81. Theuwissen E, Cranenburg EC, Knapen MH, et al. Lowdose menaquinone-7 supplementation improved extra-hepatic vitamin $\mathrm{K}$ status, but had no effect on thrombin generation in healthy subjects. Br J Nutr 2012;108:16521657.

82. Vossen LM, Schurgers LJ, van Varik BJ, et al. Menaquinone-7 supplementation to reduce vascular calcification in patients with coronary artery disease: rationale and study protocol (VitaK-CAC Trial). Nutrients 2015;7:89058915.

83. Shoji T, Nishizawa Y, Kawagishi T, et al. Atherogenic lipoprotein changes in the absence of hyperlipidemia in patients with chronic renal failure treated by hemodialysis. Atherosclerosis 1997;131:229-236.

84. Tamashiro M, Iseki K, Sunagawa O, et al. Significant association between the progression of coronary artery calcification and dyslipidemia in patients on chronic hemodialysis. Am J Kidney Dis 2001;38:64-69.

85. Shroff RC, Shanahan CM. The vascular biology of calcification. Semin Dial 2007;20:103-109.

86. Goodman WG, London G, Amann K, et al. Vascular calcification in chronic kidney disease. Am J Kidney Dis 2004;43:572-579.

87. Nishizawa Y, Shoji T, Kawagishi T, Morii H. Atherosclerosis in uremia: possible roles of hyperparathyroidism and intermediate density lipoprotein accumulation. Kidney
Int Suppl 1997;62:S9o-S92.

88. Schlemmer CK, Coetzer H, Claassen N, et al. Ectopic calcification of rat aortas and kidneys is reduced with n-3 fatty acid supplementation. Prostaglandins Leukot Essent Fatty Acids 1998;59:221-227.

89. Kanai S, Uto K, Honda K, Hagiwara N, Oda H. Eicosapentaenoic acid reduces warfarin-induced arterial calcification in rats. Atherosclerosis 2011;215:43-51.

90. Block RC, Harris WS, Reid KJ, Spertus JA. Omega-6 and trans fatty acids in blood cell membranes: a risk factor for acute coronary syndromes? Am Heart J 2008;156:1117-1123.

91. Paganelli F, Maixent JM, Duran MJ, Parhizgar R, Pieroni G, Sennoune S. Altered erythrocyte n-3 fatty acids in Mediterranean patients with coronary artery disease. Int J Cardiol 2001;78:27-32.

92. An WS, Kim SE, Kim KH, et al. Comparison of fatty acid contents of erythrocyte membrane in hemodialysis and peritoneal dialysis patients. J Ren Nutr 2009;19:267-274.

93. Son YK, Lee SM, Kim SE, et al. Association between vascular calcification scores on plain radiographs and fatty acid contents of erythrocyte membrane in hemodialysis patients. J Ren Nutr 2012;22:58-66.

94. Ruiz-Gutierrez V, Muriana FJ, Guerrero A, Cert AM, Villar J. Plasma lipids, erythrocyte membrane lipids and blood pressure of hypertensive women after ingestion of dietary oleic acid from two different sources. J Hypertens 1996;14:1483-1490.

95. Kim OY, Lee SM, An WS. Impact of blood or erythrocyte membrane fatty acids for disease risk prediction: focusing on cardiovascular disease and chronic kidney disease. Nutrients 2018;10:E1454.

96. An WS, Lee SM, Son YK, et al. Omega-3 fatty acid supplementation increases 1,25-dihydroxyvitamin D and fetuin-A levels in dialysis patients. Nutr Res 2012;32:495-502.

97. An WS, Lee SM, Son YK, et al. Effect of omega-3 fatty acids on the modification of erythrocyte membrane fatty acid content including oleic acid in peritoneal dialysis patients. Prostaglandins Leukot Essent Fatty Acids 2012;86:29-34.

98. Blacher J, Guerin AP, Pannier B, Marchais SJ, London GM. Arterial calcifications, arterial stiffness, and cardiovascular risk in end-stage renal disease. Hypertension 2001;38:938-942.

99. Hall WL, Sanders KA, Sanders TA, Chowienczyk PJ. A high-fat meal enriched with eicosapentaenoic acid reduces postprandial arterial stiffness measured by digital vol- 
ume pulse analysis in healthy men. J Nutr 2008;138:287291.

100. Nestel P, Shige H, Pomeroy S, Cehun M, Abbey M, Raederstorff $\mathrm{D}$. The n-3 fatty acids eicosapentaenoic acid and docosahexaenoic acid increase systemic arterial compliance in humans. Am J Clin Nutr 2002;76:326-330.

101. Schafer C, Heiss A, Schwarz A, et al. The serum protein alpha 2-Heremans-Schmid glycoprotein/fetuin-A is a systemically acting inhibitor of ectopic calcification. J Clin Invest 2003;112:357-366.

102. Hermans MM, Brandenburg V, Ketteler M, et al. Study on the relationship of serum fetuin-A concentration with aortic stiffness in patients on dialysis. Nephrol Dial Transplant 2006;21:1293-1299.

103. Jung JY, Hwang YH, Lee SW, et al. Factors associated with aortic stiffness and its change over time in peritoneal dialysis patients. Nephrol Dial Transplant 2010;25:40414048.

104. Stenvinkel P, Wang K, Qureshi AR, et al. Low fetuin-A levels are associated with cardiovascular death: impact of variations in the gene encoding fetuin. Kidney Int 2005;67:2383-2392. 